\title{
ENETS Consensus Guidelines for Neuroendocrine Neoplasms of the Appendix (Excluding Goblet Cell Carcinomas)
}

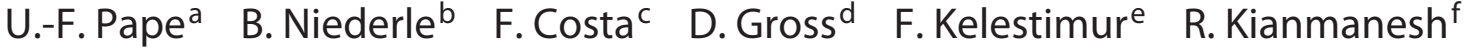 \\ U. Knigge ${ }^{g}$ K. Öberg ${ }^{\text {h }}$ M. Pavel ${ }^{a} \quad$ A.Perren ${ }^{i} \quad$ C. Toumpanakis ${ }^{j} \quad$ J. O'Connork \\ $\begin{array}{lll}\text { E. Krenning' N. Reed } & \text { D. O'Toole } & \\ & \text { D }\end{array}$ \\ all other Vienna Consensus Conference participants
}

aDepartment of Hepatology and Gastroenterology, Campus Virchow Klinikum, Charité Universitätsmedizin Berlin, Berlin, Germany; ${ }^{b}$ Department of Surgery, Medical University of Vienna, Vienna, Austria; ' Centro de Oncologia, Hospital Sírio Libanês, São Paulo, Brazil; ${ }^{d}$ Department of Endocrinology and Metabolism, Hadassah University Hospital, Mevasseret Tsion, Israel; e Department of Endocrinology, Erciyes University Medical School, Kayseri, Turkey; ${ }^{\mathrm{f}}$ Department of Surgery, CHU Robert Debré, Reims, France; ${ }^{9}$ Neuroendocrine Tumor Center of Excellence, Rigshospitalet, Copenhagen University Hospital, Copenhagen, Denmark; h Department of Medical Sciences, Endocrine Oncology Unit, University Hospital, Uppsala, Sweden; 'Institute of Pathology, University of Bern, Bern, Switzerland; jNeuroendocrine Tumour Unit, Royal Free Hospital, London, UK; kDepartment of Clinical Oncology, Institute Alexander Fleming, Buenos Aires, Argentina; 'Department of Internal Medicine, Division of Nuclear Medicine, Erasmus Medical Center, Rotterdam, The Netherlands; m Beatson Oncology Centre,

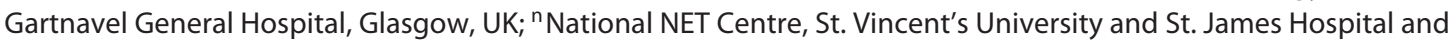
Trinity College, Dublin, Ireland

\section{Epidemiology and Prognosis}

Neuroendocrine neoplasms (NEN) of the appendix are a relatively frequent subgroup of NEN with an approximate incidence rate of $0.15-0.6 / 100,000 /$ year and with a slight female preponderance in Western series [112]. Although NEN are frequently reported [13], most cases are of an early stage [12-14]. The reported incidence has increased in more recent years $[1,6]$; however, the overall incidence rate is probably roughly within the same range between different races, although some differences have been reported $[1,12,15-18]$. Furthermore, common practice in performing appendicectomies may also influence the reported incidence of appendiceal NEN $[19,20]$.

Appendiceal NEN comprise the largest subgroup of appendiceal neoplasms with approximately $30-80 \%$ of all appendiceal neoplasms $[1,13,14,21-24]$. Mean age at diagnosis has been reported between 38 and 51 years [6, 24-26]. However, appendiceal NEN have also been reported in pediatric patients between 4.5 and 19.5 years of age $[2,4,17,27-29]$, but population-based data are not available for this special subgroup.

The prognosis of the majority of appendiceal NEN is excellent in the series that report outcome on lower tumor stages with 5 -year survival rates (YSR) of $100 \%$ or close to this $[7,14,11,25,30-32]$. However, the whole cohort including all tumor stages does not show such a favorable prognosis, with 5-YSR ranging between 70 and $85 \%[11,25,30,31,33]$. Advanced stages with distant me-

For an alphabetical list of all other Vienna Consensus Conference participants, see Appendix.

\section{KARGER}

E-Mail karger@karger.com

www.karger.com/nen
(C) 2016 S. Karger AG, Base

$0028-3835 / 16 / 1032-0144 \$ 39.50 / 0$
Dr. Ulrich-Frank Pape

Department of Internal Medicine, Division of Hepatology and Gastroenterology, Campus Charité Mitte and Virchow Klinikum, Charité Universitätsmedizin Berlin Charitéplatz 1, DE-10117 Berlin (Germany)

E-Mail ulrich-frank.pape@ charite.de 
tastases have been reported with a much poorer prognosis and a 5 -YSR of as low as $12-28 \%[1,11,14]$. However, it is not clear to which extent more 'malignant' histologies such as goblet cell carcinoids (GCC) or mixed adenoneuroendocrine carcinomas with a poorer prognosis per se were included in such series.

\section{Minimal Consensus Statement on Epidemiology and Prognosis}

Appendiceal NEN present with an incidence of 0.15$0.6 / 100,000 /$ year. They are diagnosed slightly more often in female than in male patients at an average age of $40-50$ years. Appendiceal NEN are, however, much more frequently diagnosed incidentally during appendicectomy with a rate of approximately 3-5/1,000 appendicectomies. Racial differences may occur but data are inconclusive. In contrast, malignant tumors seem to occur more often in Caucasians compared to other races. Appendiceal NEN may also rarely occur in children but apparently with an excellent long-term outcome. While at a lower stage, survival is extremely good (local disease: 5 -YSR of $95-100 \%$, regional disease: 5-YSR of $85-100 \%$ ), on the other hand, the few cases with distant metastasis present with relatively poor survival figures (5-YSR: <25\%).

From the available data, it is concluded that an appendiceal NEN $<1 \mathrm{~cm}$, with invasion up to the subserosa or mesoappendiceal invasion up to $3 \mathrm{~mm}$ and clear surgical margins poses no further risk of recurrence after appendicectomy.

Most tumors (70\%) are located at the tip of the appendix. However, tumors at the base of the appendix, tumors of 1-2 cm in diameter and tumors with deep mesoappendiceal invasion or margin invasion confer a relevant risk of recurrence, and further surgical procedures are warranted, although no data have literally proven a survival benefit of more aggressive surgery.

\section{Clinical Presentation}

Most appendiceal NEN in adults as well as in children are incidental findings in postappendicectomy specimen and therefore no characteristic tumor-specific symptomatology has been established $[5,17]$. However, symptoms that lead to appendicectomy such as right lower abdominal pain are indirectly associated with appendiceal NEN, although due to their most frequent localization at the tip of the appendix (approx. $70 \%)$ these tumors are very likely not causative of acute appendicitis [34-41]. In the rare cases of distant metastases, these may cause symptoms related to the localization of the metastases.

A carcinoid syndrome is an extreme exception in metastatic patients $[35,36,38]$ and more likely associated with an intestinal primary tumor.

Consensus Guidelines for NEN of the

Appendix

\section{Minimal Consensus Statement on Clinical Presentation}

Appendiceal NEN are rarely symptomatic in the large majority of cases due to the incidental nature of their diagnosis. However, tumors with extensive local disease or distant metastases may appear symptomatic with abdominal pain, a tumor mass effect or signs of bowel obstruction. An association with the carcinoid syndrome is extremely rare and indicates metastatic disease.

\section{Diagnostic Procedures}

Since most appendiceal NEN are incidentally diagnosed during postoperative histology, diagnostic procedures relate mostly to postoperative staging, follow-up and to the rare cases with suspected or evidenced distant metastasis.

\section{Imaging}

There are no specific diagnostic studies focusing on appendiceal NEN only, and therefore the considerations which apply to small intestinal NEN are considered to be also valid for appendiceal NEN and have not been changed since the previous version of the guidelines.

Cross-sectional imaging using CT or MRI with modern protocols should be used to rule out locoregional or distant metastasis [42-45]. NEN limited to the appendix may be detected by transabdominal ultrasonography, which in spite of its investigator-dependent limitations is the least invasive procedure but has not been validated. Endoscopy is rarely helpful, unless the tumor is locally advanced and infiltrates the cecum, which is a very rare situation; thus, colonoscopy for tumor detection is not recommended [46]. In the context of the potentially increased incidence of secondary neoplasms, general recommendations regarding colorectal cancer screening should be followed. Somatostatin receptor imaging using either indium-111-somatostatin receptor scintigraphy (including SPECT) or positron emission tomography (PET) scanning using gallium-68-labelled somatostatin analogues in combination with CT may be considered in cases where curative resection is not completely assured or where distant metastasis is suspected [45].

\section{Laboratory Tests}

Chromogranin A (CgA) can be used as a tumor marker in appendiceal NEN like in small intestinal NEN and is particularly useful to differentiate NEN from GCC since it has been described to be increased in appendiceal

Neuroendocrinology 2016;103:144-152 
Table 1. Grading classification of NEN according to the WHO 2010 classification

\begin{tabular}{lll}
\hline Grading & Ki-67 index & Mitotic rate \\
\hline G1 NET & $\leq 2 \%$ & $<2 / 10 \mathrm{HPF}$ \\
G2 NET & $3-20 \%$ & $2-20 / 10 \mathrm{HPF}$ \\
G3 NEC & $>20 \%$ & $>20 / 10 \mathrm{HPF}$ \\
\hline
\end{tabular}

NEN $[47,48]$. However, its role for regular follow-up (particularly for the detection of recurrent disease) has not been thoroughly studied. It is indicated in metastatic disease as a follow-up parameter like in other NEN. In the extremely rare patient with carcinoid syndrome, urinary 5-HIAA may be useful [49].

\section{Minimal Consensus Statement on Diagnostic Procedures}

For the majority of well-differentiated appendiceal NEN diagnosed incidentally, with a maximum diameter $<1 \mathrm{~cm}$ and $\mathrm{R} 0$ resection, no postoperative diagnostic procedure is required. For well-differentiated tumors of 1 to $<2 \mathrm{~cm}$ and $\mathrm{R} 0$ resection, there are no clear data, but a single CT or MRI of the abdomen to rule out lymph node or distant involvement may be justified. In cases with deep mesoappendiceal infiltration or angioinvasion and tumors $>2 \mathrm{~cm}$, CT or MRI of the abdomen and somatostatin receptor imaging (somatostatin receptor scintigraphy or SR-PET/CT) should be performed.

CgA may be used as a surrogate parameter in advanced metastatic appendiceal NEN but has not been particularly validated for diagnosis and follow-up of appendiceal NEN.

\section{Pathology and Genetics}

The histopathological characterization of appendiceal NEN includes immunohistochemical proof of the neuroendocrine tumor (NET) entity by immunohistochemical staining for synaptophysin and $\mathrm{CgA}$ as well as for Ki-67 to determine the proliferative capacity of the tumor [5052].

The Ki-67 index also determines the tumor grading according to the current WHO classification (table 1) [50, 52]. NEN of the appendix are usually G1 or G2 (Ki-67 index $<20 \%$ ) and thus should be considered NET [53]. Appendiceal G2 NET are considered to comprise a higher risk of recurrence and/or metastasis; however, direct proof of this is still pending and has in fact been challenged [54]. Besides WHO grading TNM staging accord- ing to either the UICC/AJCC classification or ENETS guidelines (or best according to both; table 2) is recommended $[52,53,55,56]$.

In cases of higher tumor grades, one should indeed suspect either a GCC or mixed adenoneuroendocrine carcinoma, but rare cases of a 'true' neuroendocrine carcinoma (G3 NEC) may occur. Neither is considered a NET, and thus beyond the scope of these guidelines. The management of these neoplasms should be tailored to the respective adenocarcinomas $[46,56,66]$.

\section{Stratification according to Size, Localization and Extent of Invasion}

There are no substantial changes of criteria used for stratifying therapeutic decision in appendiceal NEN since the 2011 guidelines. Thus, for an extensive discussion, this chapter refers the reader to the previously published guidelines and just summarizes the key criteria a caregiver should have available for the therapeutic decision [46].

\section{Summary of the Main Prognostic Features of Appendiceal NEN}

\section{(A) Size}

Tumors $<1 \mathrm{~cm}$ (T1a according to the UICC/AJCC classification and T1 according to the ENETS guidelines; table 2) can be cured by simple appendicectomy with an excellent almost $100 \%$ long-term survival rate in both children and adults [5, $27,28,37,57]$, although some publications have described lymph node metastasis $[14,19]$ while others have not $[38,58]$.

- Tumors $>1 \mathrm{~cm}$ but $<2 \mathrm{~cm}$ (T1b according to the UICC/AJCC classification and T2 according to the ENETS guidelines; table 2) are most challenging for decision making, because metastases seem to occur only rarely in this subgroup, but the subgroup per se comprises 5-25\% of all appendiceal NEN. However, a risk of metastasis seems to exist, particularly in cases $>1.5 \mathrm{~cm}[5,7,14,19,41,54,57-59]$.

- Tumors $>2 \mathrm{~cm}$ are rare $(<10 \%)$ but may carry a risk of metastasis of up to $40 \%[7,37,58]$ and, therefore, justify a radical oncological resection and long-term follow-up (T2 according to the UICC/AJCC classification and T3 according to the ENETS guidelines; table 2). Metastasis has been observed in some cases of these appendiceal NET [58] but not in all [60].

- Tumors extending beyond the appendix invading the peritoneum or adjacent organs (T4 according to the UICC/AJCC classification and the ENETS guidelines; table 2), infiltrating lymph nodes (N1 according to the UICC/AJCC classification and the ENETS guidelines; table 2) or metastasizing to distant organs (M1 according to the UICC/AJCC classification and the ENETS guidelines; table 2) are no longer considered a limited disease and require systemic oncological evaluation because of poorer long-term outcome $[46,53,56]$. 
Table 2. TNM staging for appendiceal NEN according to either the ENETS guidelines or the UICC/AJCC classification

\begin{tabular}{|c|c|c|}
\hline & ENETS guidelines & UICC/AJCC classification \\
\hline \multicolumn{3}{|c|}{$T$ - primary tumor } \\
\hline $\mathrm{x}$ & \multicolumn{2}{|l|}{ primary tumor not assessed/assessable } \\
\hline 0 & \multicolumn{2}{|l|}{ no evidence of any primary tumor } \\
\hline 1 & \multicolumn{2}{|l|}{$\begin{array}{l}\text { tumor } \leq 1 \mathrm{~cm} \text { with infiltration of the submucosa and muscularis } \\
\text { propria }\end{array}$} \\
\hline 2 & $\begin{array}{l}\text { tumor } \leq 2 \mathrm{~cm} \text { with infiltration of the submucosa, muscularis } \\
\text { propria and/or minimal }(\leq 3 \mathrm{~mm}) \text { infiltration of the subserosa } \\
\text { and/or mesoappendix }\end{array}$ & $\begin{array}{l}\text { tumor }>2 \mathrm{~cm} \text { but } \leq 4 \mathrm{~cm} \text { or with } \\
\text { extension into the cecum }\end{array}$ \\
\hline 3 & $\begin{array}{l}\text { tumor }>2 \mathrm{~cm} \text { and/or extensive }(>3 \mathrm{~mm}) \text { infiltration of } \\
\text { the subserosa and/or mesoappendix }\end{array}$ & $\begin{array}{l}\text { tumor }>4 \mathrm{~cm} \text { or with extension into the } \\
\text { ileum }\end{array}$ \\
\hline 4 & $\begin{array}{l}\text { tumor with infiltration of the peritoneum and/or other } \\
\text { neighboring organs }\end{array}$ & $\begin{array}{l}\text { tumor with perforation of the } \\
\text { peritoneum or invasion of other adjacen } \\
\text { structures }\end{array}$ \\
\hline N0 & \multicolumn{2}{|c|}{ no regional lymph node metastasis } \\
\hline N1 & \multicolumn{2}{|c|}{ locoregional lymph node metastasis/-es } \\
\hline \multicolumn{3}{|c|}{$M$ - distant metastasis } \\
\hline $\mathrm{Mx}$ & \multicolumn{2}{|c|}{ distant metastasis not assessed/assessable } \\
\hline M0 & \multicolumn{2}{|c|}{ no distant metastasis } \\
\hline$\overline{\mathrm{M} 1}$ & \multicolumn{2}{|l|}{ distant metastasis/-es } \\
\hline
\end{tabular}

(B) Localization within the Appendix

Most appendiceal NEN are located at the tip of the organ (60$75 \%)$, while some are located at the middle portion (5-20\%) and the smallest fraction $(<10 \%)$ at the base of the appendix. Although there is no clear correlation with outcome, incomplete resection resulting in recurrence and metastases may likely occur more frequently with an appendiceal NET located next to or at the base of the appendix $[37,46,56]$.

(C) Extent of Invasion into the Mesoappendix and Vascular Invasion

Tumor cell invasion into the mesoappendix (T2 vs. T3 stage according to the ENETS guidelines, not considered by the UICC/ AJCC classification; see table 2) can relatively frequently be observed in up to $20 \%$ of adults and up to $40 \%$ of children $[27,61$, $62]$. While an infiltration of the appendiceal serosa does not seem to be associated with poorer outcome, an invasion into the mesoappendix shows a higher rate of vascular (V1) or lymph vessel involvement (L1) than in cases without. Furthermore, an invasion depth of $>3 \mathrm{~mm}$ has been suggested to reflect the aggressiveness of the disease. Therefore, the TNM classification by the ENETS uses this criterion to distinguish T2 from T3 tumors (even in case of tumors $<2 \mathrm{~cm}$ ) [52].

The pathology report should therefore contain: pTNM stage, WHO grading, vascular (V0/1) or lymph (L0/1) vessel involvement and a statement on mesoappendiceal infiltration (and the extent of the latter).

Consensus Guidelines for NEN of the Appendix
These criteria or risk factors can then be used as a logical and likely but hitherto formally unproven rationale for decision making of whether a right-sided hemicolectomy should be recommended or whether it seems likely safe to not do so (fig. 1).

\section{Minimal Consensus Statement on Pathology and Genetics}

A histological analysis is always necessary to establish the diagnosis. Cytology may be helpful, particularly in the rare metastatic setting. The minimal ancillary tests to support the histological diagnosis include immunohistochemistry for $\mathrm{CgA}$ and synaptophysin. Both the mitotic count per $10 \mathrm{HPF}\left(2 \mathrm{~mm}^{2}\right.$, at least 40 fields at $40 \times$ magnification), evaluated in areas of highest mitotic density, and the Ki-67 index (MIB1 antibody; percentage of 2,000 cells in areas of highest nuclear labeling) should be reported (table 1). The histopathology report should allow for a correct classification according to the current WHO criteria.

The ENETS TNM staging differs for the T stages from the AJCC/UICC/WHO TNM staging for appendiceal tumors. It is strongly recommended to use the ENETS TNM classification in addition to the AJCC/UICC/WHO system and to indicate this in the pathology report (table 2). Furthermore, vascular and lymph node involvement should be stated as aides to clinical decision making (fig. 1). No genetic association has been reported thus far and, therefore, there is currently no need for any genetic testing. 
Fig. 1. Therapeutic algorithm for small appendiceal NET. V1 = Vascular invasion; L1 = lymphatic invasion; G2 = grade 2 tumor (Ki-67: 3-20\%).

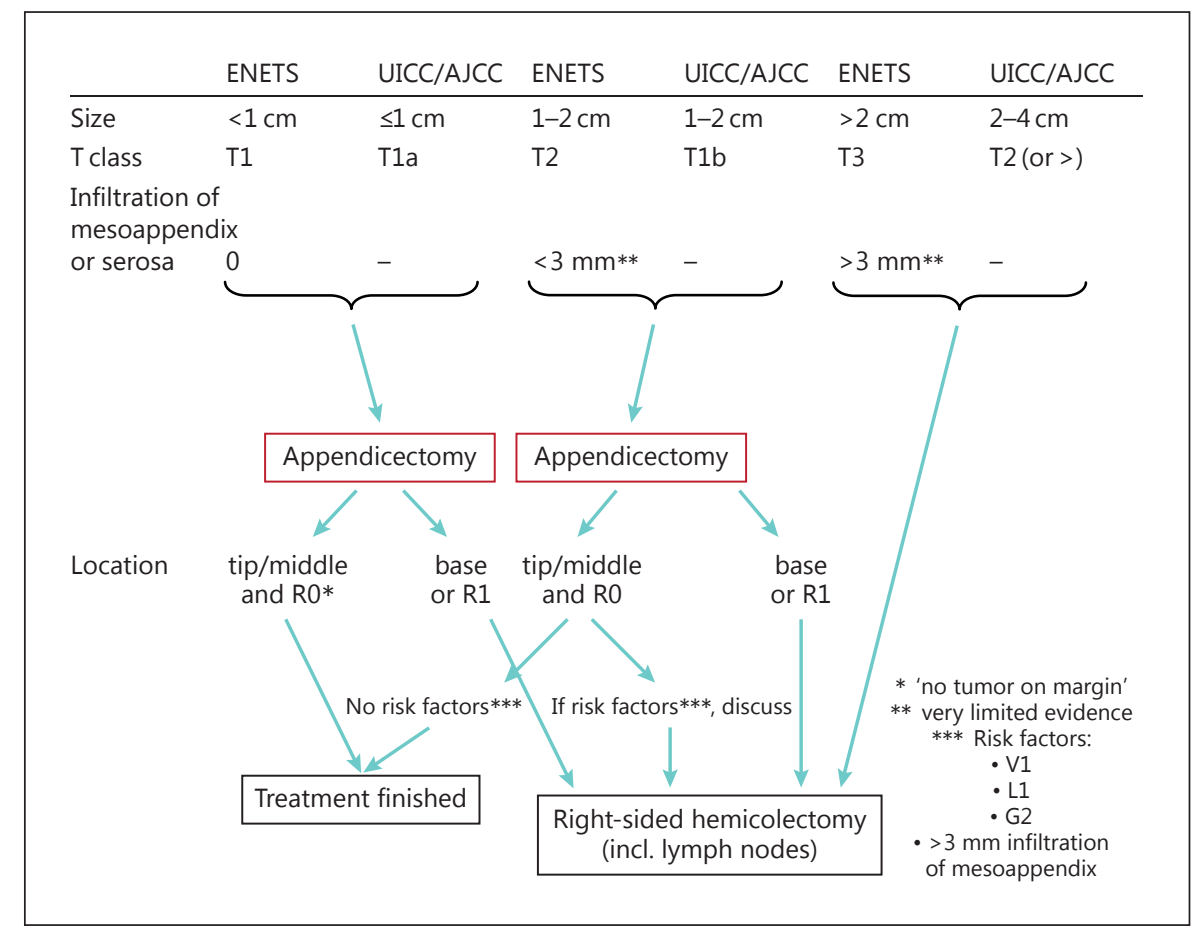

\section{Surgical Therapy}

Two surgical procedures can be applied to treat local or locoregional appendiceal NEN: simple appendicectomy and oncological right-sided hemicolectomy.

As outlined above, appendiceal NEN are frequently diagnosed incidentally at appendicectomy for suspected or manifest acute appendicitis. The NEN may either be already detected during this procedure or afterwards on histological evaluation. Similar to the staging criteria including the risk factors mentioned above, the surgical strategy should be tailored to the individual situation (fig. 1) and according to the data discussed in the section above. In general, the following statements apply to the specific situations:

1 Appendiceal NET $(\mathrm{G} 1 / 2)<2 \mathrm{~cm}$ can be cured by simple appendicectomy unless incompletely resected or if any of the below discussed additional situations occurs in which right-sided hemicolectomy should be considered or performed (R1 resection status after initial appendicectomy).

2 Appendiceal NET $(\mathrm{G} 1 / 2)>2 \mathrm{~cm}$ should be treated with oncological right-sided hemicolectomy. However, small G1/2 NET appear to be the most frequently observed clinical situation and, therefore, the arguments for decision making are specified as follows:
- T1 (ENETS) or T1a (UICC/AJCC) NET (i.e. $<1 \mathrm{~cm}$ ): generally, simple appendicectomy is curative and sufficient (if the resection status is R0). The only exception could be the extremely rare situation when the NEN is located at the base of the appendix or when a mesoappendiceal invasion $>3 \mathrm{~mm}$ is discovered histopathologically. Under these circumstances, a completion of the resection seems advisable, although a worse prognosis has not been proven and a higher complication rate than with simple appendicectomy has to be considered [5, 7, 14, 19, 41, 54, 57, 59].

- T2 (ENETS) or T1b (UICC/AJCC) NET (i.e. $>1 \mathrm{~cm}$ but $<2 \mathrm{~cm}$ ): lymph node or distant metastasis seems unlikely but possible, since it has been reported several times. Thus, long-term definitive cure can be achieved with a right-sided hemicolectomy; however, increased peri- and postoperative morbidity need to be weighed against the small but existing risk of incomplete resection by appendicectomy or late recurrence (particularly in many relatively young patients). This risk may be higher if the tumor size is $>1.5 \mathrm{~cm}$, particularly in children, but evidence is too weak to exclude patients with appendiceal NET $<1.5 \mathrm{~cm}$ from these considerations.

Additional risk factors have been defined for assisting in decision making under these circumstances: 
- WHO grading: G2

- Vascular (V1) or lymph vessel (L1) invasion

- Mesoappendiceal infiltration $>3 \mathrm{~mm}$

If one or more of these risk factors coexist, it is recommended to discuss right-sided hemicolectomy with the patients.

- T3 (ENETS) or T2 (UICC/AJCC) or higher-stage NET (i.e. $>2 \mathrm{~cm}$ ): right-sided hemicolectomy with oncological lymph node dissection is advised due to the clearly increased risk of lymph node metastasis and longterm tumor recurrence and/or distant metastasis. The operation can be performed as the initial surgical intervention or as a second intervention after initial (diagnostic) appendicectomy [60].

- Appendiceal NEC (G3, Ki-67 >20\%) should, irrespective of the tumor size, be treated using an oncological right-sided hemicolectomy and be managed as adenocarcinoma cases.

3 In pediatric patients, outcome after appendiceal NET resection has been extremely favorable in the group with tumors between 1 and $2 \mathrm{~cm}$ and even in those with tumors $>2 \mathrm{~cm}$, and thus these guidelines explicitly do not apply to this specific population. The reason for the even better outcome in the pediatric population is currently not understood $[5,63]$.

\section{Minimal Consensus Statement on Surgical Therapy}

It is generally felt that a well-differentiated appendiceal NEN $<2 \mathrm{~cm}$ is cured by appendicectomy independent of the location of the tumor. Thus, right-sided hemicolectomy is justified only in those rare tumors measuring $1-2 \mathrm{~cm}$ but with positive or unclear margins or with deep mesoappendiceal invasion (ENETS T2), higher proliferation rate (G2) and/or vascular invasion. Tumors with a diameter $>2 \mathrm{~cm}$ should be treated by right-sided hemicolectomy.

\section{Follow-Up}

In cases of curative resection of appendiceal NEN $<1$ $\mathrm{cm}$ by simple appendicectomy, no specific follow-up strategy has been recommended $[46,64]$. For cases with right-sided hemicolectomy due to a size $>1 \mathrm{~cm}$ but without proof of lymph node involvement or any other residual disease in the resected specimen, again no specific follow-up strategy seems to be necessary [65]. For cases with involvement of the lymph nodes or any cases with resected distant metastases, however, long-term followup is advised because of the proven invasiveness of the tumor. Finally, in patients with an appendiceal NEN mea- suring between 1 and $2 \mathrm{~cm}$ who have not received rightsided hemicolectomy for whatever reason (comorbidity, no consent, hesitancy, etc.) but with risk factors (i.e. localization at the base of the appendix, mesoappendiceal invasion $>3 \mathrm{~mm}$, G2 NET or vascular invasion), regular follow-up seems advisable due to the presumed risk of lymph node metastasis but any benefit for the prevention of tumor recurrence or an influence on long-term outcome is unproven [65]. It should be considered that neither the determination of surrogate parameters (i.e. CgA or 5-HIAA) nor indirect noninvasive imaging have been studied for their sensitivity for detecting metastasis or local tumor recurrence in this specific setting. Cumulative exposure to irradiation with repetitive scanning may be an argument to use MRI rather than CT scanning in younger and particularly in fertile patients (female or male) [45]. The role of colonoscopy or transabdominal ultrasound has not been established in this setting and is not recommended. However, it seems rational to apply transabdominal ultrasound to extend the intervals between MRI or CT examinations. Although unproven, the life-long awareness of the potential of these slowly growing tumors to recur should be kept in mind in appendiceal NEN $>2 \mathrm{~cm}$ or $>1 \mathrm{~cm}$ with risk factors $[46,64]$.

\section{Minimal Consensus Statement on Follow-Up}

For guidelines regarding follow-up strategies, we recommend to follow the ENETS standards of care [64].

For well-differentiated tumors, diagnosed incidentally, with a maximum diameter of $<1 \mathrm{~cm}$ and $\mathrm{R} 0$ resection, no follow-up is required.

For well-differentiated tumors of $1-2 \mathrm{~cm}$ and $\mathrm{R} 0$ resection, there are no sufficient data for a clear-cut decision. Most participants at the Consensus Conference suggested no regular followup. However, in cases with risk factors, follow-up may be considered, although a specific schedule is not recommended.

All other patients, with either tumors $>2 \mathrm{~cm}$, metastasis or additional risk factors (R1 resection), should be followed initially after 6 and 12 months postoperatively and then annually, although this approach has also not been validated.

Please also refer to the consensus guideline updates for other gastroenteropancreatic NET [67-72, this issue].

\section{Appendix}

All Other Vienna Consensus Conference Participants

Anlauf, M. (Institut für Pathologie und Zytologie, St. Vincenz Krankenhaus, Limburg, Germany); Bartsch, D.K. (Department of Surgery, Philipps University, Marburg, Germany); Baudin, E. (Institut Gustave Roussy, Villejuif, France); Capdevila, J. (Institute of Oncology, Vall d'Hebron University Hospital, Barcelona, Spain); 
Caplin, M. (Neuroendocrine Tumour Unit, Royal Free Hospital, London, UK); Cwikla, J.B. (Department of Radiology, Faculty of Medical Sciences, University of Warmia and Mazury, Olsztyn, Poland); De Herder, W.W. (Department of Internal Medicine, Division of Endocrinology, Erasmus Medical Center, Rotterdam, The Netherlands); Delle Fave, G. (Department of Digestive and Liver Disease, Ospedale Sant'Andrea, Rome, Italy); Eriksson, B. (Department of Endocrine Oncology, University Hospital, Uppsala, Sweden); Falconi, M. (Department of Surgery, San Raffaele Hospital, Università Vita e Salute, Milan, Italy); Ferolla, P. (NET Center, Umbria Regional Cancer Network, Università degli Studi di Perugia, Perugia, Italy); Ferone, D. (Department of Endocrine and Metabolic Sciences, University of Genoa, Genoa, Italy); GarciaCarbonero, R. (Medical Oncology Department, Hospital Universitario Doce de Octubre, Madrid, Spain); Ito, T. (Pancreatic Diseases Branch, Kyushu University Hospital, Kyushu School of Medicine, Fukuoka, Japan); Jensen, R.T. (Digestive Diseases Branch, NIH, Bethesda, Md., USA); Kaltsas, G. (Department of Pathophysiology, Division of Endocrinology, National University of Athens, Athens, Greece); Klöppel, G. (Institute of Pathology, Technische Universität München, Munich, Germany); Kos-Kudla, B. (Department of Endocrinology, Medical University of Silesia, Katowice, Poland); Kwekkeboom, D. (Department of Internal Medicine, Di- vision of Nuclear Medicine, Erasmus Medical Center, Rotterdam, The Netherlands); Pascher, A. (Department of Visceral and Transplant Surgery, Campus Virchow Klinikum, Charité Universitätsmedizin Berlin, Berlin, Germany); Ramage, J.K. (Gastroenterology Department, Hampshire Hospitals NHS Trust, Hampshire, UK); Raymond, E. (Oncologie Médicale, Hôpitaux Universitaires Paris Nord Val de Seine, Paris, France); Rindi, G. (Institute of Anatomic Pathology, Policlinico A. Gemelli, Università Cattolica del Sacro Cuore, Rome, Italy); Ruszniewski, P. (Department of Gastroenterology, Beaujon Hospital, Clichy, France); Sedlackova, E. (Department of Oncology, First Faculty of Medicine and General Teaching Hospital, Prague, Czech Republic); Sorbye, H. (Department of Oncology, Haukeland University Hospital, Bergen, Norway); Sundin, A. (Department of Radiology, Section for Molecular Imaging, University Hospital, Uppsala, Sweden); Taal, B. (Netherlands Cancer Centre, Lijnden, The Netherlands); Weber, W. (Department of Radiology, Memorial Sloan Kettering Cancer Center, New York, N.Y., USA); Wiedenmann, B. (Department of Hepatology and Gastroenterology, Campus Virchow Klinikum, Charité Universitätsmedizin Berlin, Berlin, Germany); Zheng-Pei, Z. (Department of Endocrinology, Peking Union Medical College Hospital, Beijing, China).

\section{References}

1 Yao JC, Hassan M, Phan A, et al: One hundred years after 'carcinoid': epidemiology of and prognostic factors for neuroendocrine tumors in 35,825 cases in the United States. J Clin Oncol 2008;26:3063-3072.

2 Allan B, Davis J, Perez E, et al: Malignant neuroendocrine tumors: incidence and outcomes in pediatric patients. Eur J Pedatr Surg 2013; 23,394-399.

3 Anwar K, Desai M, Al-Bloushi N, et al: Prevalence and clinicopathological characteristics of appendiceal carcinoids in Sharjah (United Arab Emirates). World J Gastrointest Oncol 2014;6:253-256.

4 Benedix F, Reimer A, Gastinger I, et al: Primary appendiceal carcinoma - epidemiology, surgery and survival: results of a German multi-center study. EJSO 2010;36:763-771.

5 Boxberger N, Redlich A, Böger C, et al: Neuroendocrine tumors of the appendix in children and adolescents. Pediatr Blood Cancer 2013;60:65-70.

6 Ellis L, Shale MJ, Coeman MP: Carcinoid tumors of the gastrointestinal tract: trends in incidence in England since 1971. Am J Gastroenterol 2010;105:2563-2569.

7 In't Hoff $\mathrm{KH}$, van der Wal HC, Kazemier G, et al: Carcinoid tumour of the appendix: an analysis of 1,485 consecutive emergency appendectomies. J Gastrointest Surg 2008;12: 1436-1438.

8 Hauso O, Gustafsson BI, Kidd M, et al: Neuroendocrine tumor epidemiology: contrasting Norway and North America. Cancer 2008; 113:2655-2664.
9 Lepage C, Rachet B, Coleman MP: Survival from malignant digestive endocrine tumors in England and Wales: a population based study. Gastroenterology 2007;132:899-904.

10 Modlin IM, Lye KD, Kidd M: A five-decade analysis of 13,715 carcinoid tumors. Cancer 2003;97:934-959.

11 Quaedvlieg PF, Visser O, Lamers CB, et al: Epidemiology and survival in patients with carcinoid disease in the Netherlands. An epidemiological study with 2,391 patients. Ann Oncol 2001;12:1295-1300.

12 Tsai HJ, Wu CC, Tsai CR, et al: The epidemiology of neuroendocrine tumors in Taiwan: a nation-wide cancer registry-based study. PLoS One 2013;8:e62487.

13 Gouffon M, Iff S, Ziegler K, et al: Diagnosis and workup of 522 consecutive patients with neuroendocrine neoplasms in Switzerland. Swiss Med Wkly 2014;144:w13924.

14 Hsu C, Rashid A, Xing Y, et al: Varying malignant potential of appendiceal neuroendocrine tumors: importance of histologic subtype. J Surg Oncol 2013;107:136-143.

15 Graham RPD, Williams NP, West KA: Primary epithelial tumours of the appendix in a black population: a review of cases. World J Gastroenterol 2009;15:1472-1474.

16 Ito T, Sasano H, Tanaka M, et al: Epidemiological study of gastroenteropancreatic neuroendocrine tumors in Japan. J Gastroenterol 2010;45:234-243.

17 Scott A, Upadhyay V: Carcinoid tumors of the appendix in children in Auckland, New Zealand: 1965-2008. NZ Med J 2011;124:56-60.
18 Zhang X, Ma L, Bao H, et al: Clinical, pathological and prognostic characteristics of gastroenteropancreatic neuroendocrine neoplasms in China: a retrospective study. BMC Endocr Disord 2014;14:54.

19 Mullen JT, Savarese DMF: Carcinoid tumors of the appendix: a population-based study. J Surg Oncol 2011;104:41-44.

20 Crea N, Pata G, Di Betta E, et al: High incidence of appendix carcinoid tumors among candidates for bariatric surgery: diagnostic and therapeutic implications. Obes Surg 2011;21:151-156.

21 Gustaffson BI, Siddique L, Chan A, et al: Uncommon cancers of the small intestine, appendix and colon: an analysis of SEER 19732004, and current diagnosis and therapy. Int J Oncol 2008;33:1121-1131.

22 Niederle MB, Hackl M, Kaserer K, et al: Gastroenteropancreatic neuroendocrine tumours: the current incidence and staging based on the WHO and European Neuroendocrine Tumour Society classification: an analysis based on prospectively collected parameters. Endocr Relat Cancer 2010;17:909918.

23 Helland SK, Prosch AM, Viste A: Carcinoid tumours in the gastrointestinal tract - a population-based study from western Norway. Scand J Surg 2006;95:158-161.

24 Lepage C, Bouvier AM, Manfredi S, et al: Incidence and management of primary malignant small bowel cancers: a well-defined French population study. Am J Gastroenterol 2006;101:2826-2832. 
25 García-Carbonero R, Capdevila J, CrespoHerrero G, et al: Incidence, patterns of care and prognostic factors for outcome of gastroenteropancreatic neuroendocrine tumors (GEP-NETs): results from the National Cancer Registry of Spain (RGETNE). Ann Oncol 2010;21:1794-1803.

26 Ploeckinger U, Kloeppel G, Wiedenmann B, et al: The German NET registry: an audit on the diagnosis and therapy of neuroendocrine tumours. Neuroendocrinology 2009;90:349363.

27 Prommegger R, Obrist P, Ensinger C, et al: Retrospective evaluation of carcinoid tumors of the appendix in children. World J Surg 2002;26:1489-1492.

28 Parkes SE, Muir KR, Sheyyab M, et al: Carcinoid tumours of the appendix in children 1957-1986: incidence, treatment and outcome. Br J Surg 1993;80:502-504.

29 Kulkarni KP, Sergi C: Appendix carcinoids in childhood: long-term experience at a single institution in Western Canada and systematic review. Pediatr Int 2013;55:157-162.

30 McGory ML, Maggard MA, Kang H, et al: Malignancies of the appendix: beyond case series reports. Dis Colon Rectum 2005;48: 2264-2271.

31 Landry CS, Woodall C, Scoggins, et al: Analysis of 900 appendiceal carcinoid tumors for a proposed predictive staging system. Arch Surg 2008;143:664-670.

32 Moertel CG, Dockerty MB, Judd ES: Carcinoid tumors of the vermiform appendix. Cancer 1968;21:270-278.

33 McCusker ME, Cote TR, Clegg LX, et al: Primary malignant neoplasms of the appendix: a population-based study from the surveillance, epidemiology and end-results program, 1973-1998. Cancer 2002;94:33073312.

34 Niederle MB, Niederle B: Diagnosis and treatment of gastroenteropancreatic neuroendocrine tumors: current data on a prospectively collected, retrospectively analyzed clinical multicenter investigation. Oncologist 2011; 16:602-613.

35 Goede AC, Caplin ME, Winslet MC: Carcinoid tumour of the appendix. Br J Surg 2003; 90:1317-1322.

36 Groth SS, Virnig BA, Al-Refaie WB, et al: Appendiceal carcinoid tumors: predictors of lymph node metastasis and the impact of right hemicolectomy on survival. J Surg Oncol 2011;103:39-45.

37 Moertel CG, Weiland LH, Nagorney DM, et al: Carcinoid tumor of the appendix: treatment and prognosis. N Engl J Med 1987;317: 1699-1701.

38 Stinner B, Rothmund M: Neuroendocrine tumours (carcinoids) of the appendix. Best Pract Res Clin Gastroenterol 2005;19:729_ 738.

39 Deans GT, Spence RA: Neoplastic lesions of the appendix. Br J Surg 1995;82:299-306.
40 O'Donnell ME, Carson J, Garstin WIH, et al: Surgical treatment of malignant carcinoid tumours of the appendix. Int J Clin Pract 2007; 61:431-437.

41 Shapiro R, Eldar S, Sadot E, et al: Appendiceal cracinoid at a large tertiary center: pathologic findings and long-term follow-up evaluation. Am J Surg 2011;201:805-808.

42 Coursey CA, Nelson RC, Moreno RD, et al: Carcinoid tumours of the appendix: are these tumors identifiable prospectively on preoperative CT? Am Surg 2010;76:273-275.

43 Debnath D, Rees J, Myint F: Are we missing diagnostic opportunities in cases of carcinoid tumors of the appendix? Surgeon 2008;6:266272.

44 Pickhardt PJ, Levy AD, Rohrmann CA, et al: Primary neoplasms of the appendix: radiologic spectrum of disease with pathologic correlation. Radiographics 2003;23:645-662.

45 Virgone C, Cecchetto G, Alagio A, et al: Appendiceal neuroendocrine tumours in childhood: Italian TREP project. J Pediatr Gastroenterol Nutr 2014;58:333-338.

46 Pape UF, Perren A, Niederle B, et al: ENETS consensus guidelines for the management of patients with neuroendocrine neoplasms from the jejuno-ileum and the appendix including goblet cell carcinomas. Neuroendocrinology 2012;95:135156.

47 Prommegger R, Ensinger C, Adlassnig C, et al: Catestatin - a novel neuropeptide in carcinoid tumors of the appendix. Anticancer Res 2004;24:311-316.

48 Modlin IM, Kidd M, Latich I, et al: Genetic differentiation of appendiceal tumor malignancy: a guide for the perplexed. Ann Surg 2006;244:52-60.

49 O'Toole D, Grossman A, Gross D, et al: ENETS consensus guidelines for the standards of care in neuroendocrine tumors: biochemical markers. Neuroendocrinology 2009;90:194-202.

50 Klimstra DS, Arnold R, Capella C, et al: Bosman FT, Carneiro F, Hruban RH, Theise ND (eds): WHO Classification of Tumours of the Digestive System. Lyon, IARC, 2010.

51 Sobin LH, Gospodarowicz MK, Wittekind C (eds): TNM Classification of Malignant Tumours. Chichester, Wiley and Blackwell, 2009.

52 Rindi G, Klöppel G, Couvelard A, et al: TNM staging of midgut and hindgut (neuro)endocrine tumors: a consensus proposal including a grading system. Virchows Arch 2007;451: $757-762$.

53 Tang LH, Shia J, Soslow RA, et al: Pathologic classification and clinical behavior of the spectrum of goblet cell carcinoid tumors of the appendix. Am J Surg Pathol 2008;32: 1429-1443.

54 Volante M, Daniele L, Asioli F, et al: Tumor staging but not grading is associated with adverse clinical outcome in neuroendocrine tumors of the appendix. Am J Surg Pathol 2013; 37:606-612.
55 Washington MK, Tang LH, Berlin J, et al: Protocol for the examination of specimens from patients with neuroendocrine tumors (carcinoid tumors) of the appendix. Arch Pathol Lab Med 2010;134:171-175.

56 Tang LH: Epithelial neoplasms of the appendix. Arch Pathol Lab Med 2010;134:16121620.

57 Moertel CG, Weiland LH, Telander RL: Carcinoid tumor of the appendix in the first two decades of life. J Pediatr Surg 1990;25:10731075.

58 Fornaro R, Frascio M, Sticchi S, et al: Appendectomy or right hemicolectomy in the treatment of appendiceal carcinoid tumors? Tumori 2007;93:587-590.

59 Alexandraki KI, Griniatsos J, Bramis KI, et al: Clinical value of right hemicolectomy for appendiceal carcinoids using pathologic criteria. J Endocrinol Invest 2011;34:255-259.

60 Bamboat ZM, Berger DL: Is right hemicolectomy for 2.0-cm appendiceal carcinoids justified? Arch Surg 2006;141:349-352.

61 Dunn JP: Carcinoid tumours of the appendix: 21 cases, with a review of the literature. NZ Med J 1982;95:73-76.

62 Rossi G, Valli R, Bertolini F, et al: Does mesoappendix infiltration predict a worse prognosis in incidental neuroendocrine tumors of the appendix? A clinicopathologic and immunohistochemical study of 15 cases. Am J Clin Pathol 2003;120:706-711.

63 Henderson L, Fehily C, Folaranmi S, et al: Management and outcome of neuroendocrine tumours of the appendix - a two centre UK experience. J Pediatr Surg 2014;49:15131517.

64 Arnold R, Chen YJ, Costa F, et al: ENETS consensus guidelines for the standards of care in neuroendocrine tumours: follow-up and documentation. Neuroendocrinology 2009;90: 227-233.

65 Murray SE, Lloyd RV, Sippel RS, et al: Postoperative surveillance of small appendiceal carcinoid tumors. Am J Surg 2014;207:342345 .

66 Lamarca A, Nonaka D, Lopez Escola C, Hubner RA, O'Dwyer S, Chakrabarty B, Fulford P, Valle JW: Appendiceal goblet cell carcinoids: management considerations from a reference peritoneal tumour service centre and ENETS Centre of Excellence. Neuroendocrinology DOI:10.1159/000440725.

67 Delle Fave G, O’Toole D, Sundin A, Taal B, Ferolla P, Ramage JK, Ferone D, Ito T, Weber W, Zheng-Pei Z, De Herder WW, Pascher A, Ruszniewski P; all other Vienna Consensus Conference participants: ENETS consensus guidelines update for gastroduodenal neuroendocrine neoplasms. Neuroendocrinology 2016;103:119-124.
Consensus Guidelines for NEN of the Appendix
Neuroendocrinology 2016;103:144-152 DOI: $10.1159 / 000443165$ 
68 Niederle B, Pape UF, Costa F, Gross D, Kelestimur F, Knigge U, Öberg K, Pavel M, Perren A, Toumpanakis C, O'Connor J, O’Toole D, Krenning E, Reed N, Kianmanesh R; all other Vienna Consensus Conference participants: ENETS consensus guidelines update for neuroendocrine neoplasm of the jejunum and ileum. Neuroendocrinology 2016;103:125138.

69 Ramage JK, De Herder WW, Delle Fave G, Ferolla P, Ferone D, Ito T, Ruszniewski P, Sundin A, Weber W, Zheng-Pei Z, Taal B, Pascher A; all other Vienna Consensus Conference participants: ENETS consensus guidelines update for colorectal neuroendocrine neoplasms. Neuroendocrinology 2016; 103:139-143.
70 Falconi M, Eriksson B, Kaltsas G, Bartsch DK, Capdevila J, Caplin M, Kos-Kudla B, Kwekkeboom D, Rindi G, Klöppel G, Reed N, Kianmanesh R, Jensen RT; all other Vienna Consensus Conference participants: ENETS consensus guidelines update for the management of patients with functional pancreatic neuroendocrine tumors and non-functional pancreatic neuroendocrine tumors. Neuroendocrinology 2016;103:153-171.
71 Pavel M, O'Toole D, Costa F, Capdevila J, Gross D, Kianmanesh R, Krenning E, Knigge U, Salazar R, Pape UF, Öberg K; all other Vienna Consensus Conference participants: ENETS consensus guidelines update for the management of distant metastatic disease of intestinal, pancreatic, bronchial neuroendocrine neoplasms (NEN) and NEN of unknown primary site. Neuroendocrinology 2016;103:172-185.

72 Garcia-Carbonero R, Sorbye H, Baudin E, Raymond E, Wiedenmann B, Niederle B, Sedlackova E, Toumpanakis C, Anlauf M, Cwikla JB, Caplin M, O'Toole D, Perren A; all other Vienna Consensus Conference participants: ENETS consensus guidelines for high-grade gastroenteropancreatic neuroendocrine tumors and neuroendocrine carcinomas. Neuroendocrinology 2016;103:186-194. 